\title{
TraduÇáo
}

\section{A Filosofia da Ciência de Bas van Fraassen e o Seu Voluntarismo Epistêmico, de KathleEn OKruhlik ${ }^{1}$}

Alessio Gava ${ }^{2}$

Resumo: A visão antirrealista acerca da ciência de Bas van Fraassen desempenhou um papel determinante no desenvolvimento da filosofia da ciência recente. Particularmente, seu empirismo construtivo tem sido amplamente discutido e criticado, nas revistas especializadas, e constitui um tópico comumente abordado nos programas das disciplinas de filosofia da ciência. Outros aspectos do empirismo de van Fraassen são menos conhecidos. Entre eles, sua abordagem empirista às leis científicas, sua reavaliação, relativamente recente, do que significa ser um empirista e seu estruturalismo empirista. O presente estudo visa a oferecer uma panorâmica desses diferentes aspectos do empirismo de van Fraassen e mostrar como estão relacionados entre si. Detém-se, ainda, sobre a natureza do voluntarismo epistêmico de van Fraassen e seu nexo com a filosofia da ciência empirista desse autor.

Palavras-chave: Antirrealismo. Empirismo construtivo. Estruturalismo empirista. van Fraassen. Voluntarismo epistêmico.

${ }^{1}$ Publicado originariamente em Philosophy Compass, v. 9, n. 9, 2014, p. 653-661. Gostaria de registrar meu agradecimento a Kathleen Okruhlik, autora do artigo original, Joshua Tufts, publishing manager da revista Philosophy Compass, e Richard Claros, do editorial office da mesma revista, por terem autorizado a tradução e por terem sido táo gentis e atenciosos comigo, desde o primeiro contato. A autora é professora Emérita do Department of Philosophy, Stevenson Hall, The University of Western Ontario, London - Canada.

2 Mestre e Doutor em Lógica e Filosofia da Ciência pela Universidade Federal de Minas Gerais (UFMG), Belo Horizonte, MG - Brasil. (D) http://orcid.org/0000-0002-0426-8392. E-mail: alessiogava@yahoo.it.

https://doi.org/10.1590/0101-3173.2021.v44n4.30.p375

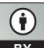

This is an open-access article distributed under the terms of the Creative Commons Attribution License. 


\section{INTRODUÇÁo}

Ao que parece, a maioria dos filósofos da ciência não concorda com Bas van Fraassen sobre praticamente nada. Entretanto, a influência desse autor na filosofia da ciência tem sido enorme e, em larga parte, benéfica. Em grande medida, essa influência se deve à ousadia de suas afirmaçóes, à força de seus argumentos e à habilidade de expressá-los em um estilo claro, envolvente e, com frequência, bastante agradável. Mas, além disso, ele é uma fonte de ideias, um perfeito contraste e um alvo valioso para aqueles que carregam visóes diferentes - especialmente, os realistas científicos das mais variadas espécies.

Van Fraassen, evidentemente, não é um realista, e sim um empirista radical. Com efeito, ele define o objetivo da ciência em termos de adequação empírica e mais nada. Outros têm oferecido um elenco de objetivos adicionais, com verdade e poder explicativo frequentemente no topo da lista, afirmando ser esses constitutivos da ciência. Van Fraassen defende o contrário, que eleger a adequação empírica como meta da atividade científica nos fornece tudo aquilo que serve para dar conta da prática e do sucesso da ciência, sem precisar assumir a bagagem extra e o risco epistêmico que a verdade comporta. E acrescenta que a explicação é um prazer antropocêntrico, mais do que um objetivo definitório da ciência. Trata-se de uma resposta a uma questão-porquê, um uso da ciência para fins de satisfazer certos desejos muito específicos e dependentes do contexto. $\mathrm{O}$ que consideramos ser uma explicação adequada depende em parte de quâo bem essa satisfaz tais desejos, o que explica por que van Fraassen a vê como um prazer antropocêntrico, mais do que como um propósito da ciência propriamente dito.

A definição do objetivo da ciência como sendo a adequação empírica (e mais nada) representa o cerne do "empirismo construtivo" de van Fraassen: quando evocamos uma realidade subjacente e inobservável, para dar conta dos objetos, eventos e processos que podemos observar, sem a mediação de algum instrumento, estamos nos aventurando fora do domínio da ciência, no reino da metafísica. A meta da ciência é salvar os fenômenos e não explicá-los, fazendo referência a qualquer tipo de realidade oculta.

Trata-se de um relato da ciência bastante austero - que está associado a uma forma de voluntarismo epistêmico bem abrangente. Não devemos cometer o erro de misturar a filosofia da ciência de van Fraassen com a sua epistemologia, mas o nosso entendimento de sua particular filosofia da ciência sairá enriquecido, se levarmos em conta a natureza de seu voluntarismo. 


\section{O Volutarismo Epistêmico}

Em 1984, van Fraassen publicou, no Journal of Philosophy, o artigo "Belief and the Will". Nele, rejeitou as concepçóes comuns de crença, pois todas elas "[...] pressupóem que quando eu expresso um julgamento epistêmico, estou descrevendo meu próprio estado psicológico - declarando um enunciado de fato autobiográfico.” (VAN FRAASSEN, 1984, p. 253). Van Fraassen defendia que deveríamos substituir essa visão (descritivista) do julgamento epistêmico por uma que aproximasse mais a expressão de uma crença com o fazer uma promessa:

Do mesmo modo, quando expresso minha opiniáo, convido o mundo a confiar em minha integridade e a inferir disso qual aconselhamento para mim e para qualquer outro em circunstâncias parecidas [...] eu consideraria ser o melhor naquele momento. [...] Devo manter meu próprio compromisso cognitivo do mesmo modo que devo atentar-me a expressóes de comprometimento de qualquer tipo. (VAN FRAASSEN, 1984, p. 255, grifos da autora).

Essa é uma primeira afirmação do voluntarismo epistêmico de van Fraassen. A crença tem mesmo a ver com a vontade e, mais especificamente, com um comprometimento com certos modos de lidar com o mundo. Aquilo que pode não resultar imediatamente óbvio, no início, é que o tipo de voluntarismo que ele endossa é em grande medida de caráter existencialista. Suas frequentes alusóes a William James, especialmente em obras anteriores, poderiam levar alguém a pensar que o voluntarismo de van Fraassen seja essencialmente pragmatista americano, em sua origem e natureza. Entretanto, em trabalhos posteriores, a influência de pensadores existencialistas, particularmente Sartre e um punhado de teólogos, se torna cada vez mais explícita. Qualquer tensão aparente é eliminada (ou, pelo menos, sai bastante enfraquecida), ao lembrarmos que os antecessores citados por van Fraassen, em seu artigo de 1984 - Santo Agostinho, Blaise Pascal e William James constam também em histórias do existencialismo como precursores daquela tradição. Deveríamos, outrossim, notar que os existencialistas se utilizam com frequência da linguagem do "engajamento" e do "comprometimento", a linguagem que van Fraassen usa, no contexto de seu próprio voluntarismo.

A epistemologia voluntarista não faz parte do empirismo construtivo e tampouco do empirismo estruturalista que van Fraassen desenvolve posteriormente, mas veremos que epistemologia e filosofia da ciência se complementam 
mutuamente. A permissividade da epistemologia voluntarista de van Fraassen representa um complemento natural à sua filosofia da ciência deveras austera; e a austeridade dessa última permite que a vontade tenha um alcance considerável.

\section{O EMPIRISMo Construtivo}

O empirismo contrutivo, a posição pela qual van Fraassen é mais conhecido, é descrito e defendido em seu livro de 1980, The Scientific Image:

A ciência tem por objetivo nos fornecer teorias que sejam empiricamente adequadas; e a aceitação de uma teoria envolve, como crença, apenas a de que essa é empiricamente adequada. Esse é o enunciado da posição antirrealista que defendo. Vou chamá-la empirismo construtivo. (VAN FRAASSEN, 1980, p. 10, grifos do autor).

Uma teoria é dita empiricamente adequada "[...] exatamente se aquilo que ela diz acerca das coisas e dos eventos observáveis do mundo é verdadeiro - exatamente se ela 'salva os fenômenos'." (VAN FRAASSEN, 1980, p. 12). Existem semelhanças entre a versão fraasseniana de antirrealismo e aquela dos empiristas lógicos da qual é sucessora, mas há diferenças igualmente importantes. O empirismo lógico foi desenvolvido no interior da tradição conhecida como sintática, a qual identifica uma teoria com um conjunto bem determinado de sentenças especificadas por meio de uma certa linguagem. Van Fraassen, ao contrário, adota a abordagem semântica, que identifica uma teoria com uma classe de modelos. Esses modelos podem ser descritos através de uma variedade de linguagens, nenhuma das quais é privilegiada. Na ciência, as estruturas são tipicamente definidas através da matemática e escolhidas por causa da relação entre a estrutura dos modelos e aquela dos fenômenos que a ciência visa a representar.

A definição mais completa e rigorosa de adequação empírica fornecida por van Fraassen reflete seu comprometimento com a abordagem semântica:

Apresentar uma teoria significa especificar uma família de estruturas, seus modelos; e, em segundo lugar, especificar certas partes desses modelos (as subestruturas empiricas) como candidatas à representação direta dos fenômenos observáveis. Podemos chamar de aparências as estruturas que podem ser descritas em relatos experimentais e de mediçáo: a teoria é empiricamente adequada se possui algum modelo tal que todas as aparências sejam isomórficas a subestruturas empíricas daquele modelo. (VAN FRAASSEN, 1980, p. 64, grifos do autor). 
Dado que o objetivo da ciência está definido em termos de adequação empírica (apenas), a aceitação de uma teoria não envolve a crença de que a mesma seja verdadeira. Quando aceitamos uma teoria, nós nos comprometemos com o uso dela, mas a única crença exigida pela aceitação da teoria é a de que suas consequências observacionais sejam verdadeiras. É importante notar que o empirismo construtivo não requer que nos mantenhamos agnósticos acerca do estatuto das entidades teóricas. Essa é uma questão de escolha. Entretanto, se escolhermos nos tornar acreditadores, estaremos desse modo abandonando a ciência e entrando no reino da intepretação ou da metafísica.

Os empiristas lógicos tinham privilegiado os termos observacionais, no interior da linguagem científica. Van Fraassen, diversamente, privilegia aqueles objetos, eventos e processos no mundo que são observáveis por observadores humanos oportunamente localizados e cujo aparelho sensorial está funcionando normalmente e sem a ajuda de instrumentos. Esses são os fenômenos que a ciência deve salvar. (No caso em que a nossa comunidade epistêmica fosse ampliada de modo a incluir nela criaturas não humanas, dotadas de um aparelho sensorial diferente, a abrangência dos fenômenos também poderia ser ampliada).

Que o termo "fenômeno" se refira não apenas a objetos e eventos que tenham sido efetivamente observados, mas sim a todos aqueles observáveis, é um fato importante. Assim, a "observabilidade" é definida de modo restrito, na medida em que apenas observações humanas não mediadas contam, e definida de modo abrangente, na medida em que os fenômenos não necessitam ser observados de fato. Os dinossauros contam como observáveis, porque, se algum humano tivesse se encontrado na mesma época e no mesmo lugar que eles, teria conseguido observá-los, sem mediação, através de seus sentidos. Planetas em galáxias distantes contariam como observáveis por razôes similares. Afirmações a propósito da adequação empírica, portanto, vão além da experiência efetiva e envolvem uma porção significativa de risco epistêmico, embora o risco não seja tão grande quanto aquele que é acarretado pela afirmação de que as nossas teorias são verdadeiras.

Em um trabalho sucessivo (VAN FRAASSEN, 2008, p. 93 e seguintes), van Fraassen discute o papel que os instrumentos (como, por exemplo, o microscópio) desempenham no tocante à observação. Sua afirmação é a de que esses não abrem "janelas para o mundo oculto", como dizem os realistas; pelo contrário, agem como "engenhos de criação". Eles criam novos fenômenos, dos quais a ciência deve dar conta. 


\section{As Leis da Natureza}

A explicação antirrealista de van Fraassen das leis da natureza é desenvolvida em seu livro de 1989, Laws and Symmetry. Ele defende que nenhuma descrição metafísica dessas leis em termos de universalidade e necessidade pode funcionar. Com efeito, de acordo com van Fraassen, náo existem leis da natureza. O que existem são apenas simetrias, em nossos modelos teóricos.

No capítulo 7, intitulado "Rumo a uma Nova Epistemologia" ("Towards a New Epistemology"), van Fraassen faz referência direta ao artigo de 1984, "Belief and the Will", o qual foi mencionado anteriormente. Aqui (no livro de 1989), ele aborda o seu próprio voluntarismo epistêmico, usando o lema "A racionalidade nada mais é do que irracionalidade com rédeas". A ideia é explicada, tomando como referência uma distinçáo entre os conceitos prussiano e inglês de lei, atribuída ao juiz da Suprema Corte (Americana), Oliver Wendell Holmes: na lei prussiana, tudo aquilo que não é expressamente permitido é proibido; já na lei inglesa, tudo aquilo que não é expressamente proibido é permitido.

De modo análogo, assinala van Fraassen, podemos distinguir entre uma concepçáo prussiana e uma inglesa de racionalidade. De acordo com a concepção prussiana, é racional acreditar naquilo que um indivíduo é racionalmente forçado a acreditar; de acordo com a concepção inglesa, aquilo em que é racional acreditar inclui tudo aquilo que um indivíduo não é racionalmente forçado a não acreditar. Van Fraassen, evidentemente, opta pela perspectiva inglesa. Isso significa que existe margem considerável para uma intervenção da vontade, quando se trata de escolher modelos teóricos. Tais escolhas não são determinadas apenas pelo conjunto de evidências empíricas, mais a lógica.

Segundo van Fraassen, escolher um modelo pressupóe assunçôes substanciais: uma seleção implícita de certos parâmetros como sendo os únicos relevantes e uma assunção tácita de estrutura, no espaço paramétrico. Se não tivermos isso presente, argumenta ele,

[...] paradoxos nos chamam de volta à razáo - respeitar simetrias em um modelo do problema leva à quebra de simetrias em um outro modelo. Tão logo damos o primeiro passo, as simetrias já nos levam em uma poderosa corrente, mas a natureza poderia muito bem ter exigido de nós um primeiro passo diferente, ou a imersáo em uma outra corrente. 
Os fatos são ambíguos. É inútil desejar presciência: qual definição dos fatos atuais será justificada pelos fatos futuros? Por outro lado, nossos modelos dos fatos não são tão ambíguos; é melhor que não o sejam. Escolher é portanto um risco. Eliminar o risco significa deixar de teorizar completamente. Essa é uma das liçóes desses paradoxos. (VAN FRAASSEN, 1989, p. 317).

O título da seção onde se dá essa discussão reflete o caráter existencial da escolha de modelos; chama-se "A Ética da Ambiguidade" ("The Ethics of Ambiguity"), uma referência direta ao famoso livro de Simone de Beauvoir sobre a ética existencial.

\section{O EMpirismo COMo "STance"}

The Empirical Stance foi publicado em 2002. No livro, van Fraassen repudia suas afirmaçóes anteriores, segundo as quais os empiristas defenderiam que a experiência é a nossa fonte única e exclusiva de informação sobre o mundo. Aliás, até expressa surpresa por ter escrito uma coisa dessas e por ter tentado desenvolver uma filosofia da ciência empirista, sem ter-se detido seriamente para refletir sobre o que seria o empirismo. Sua nova posição é esta: adotar a stance empirista significa exibir certas atitudes, que incluem tomar as ciências empíricas como paradigma de racionalidade e recusar pedidos de explicaçóes adicionais (por exemplo, pedidos que levariam à metafísica).

Tratar de adotar "stances" e exibir atitudes está em sintonia com outras manifestaçôes do voluntarismo epistêmico, as quais foram mencionadas anteriormente. E quando a discussão se volta para as revoluções científicas, o voluntarismo apresenta um sabor explicitamente sartriano - especialmente (conforme veremos a seguir) na explicação das condiçôes que tornam possível uma mudança de paradigma. As revoluçôes científicas póem um tipo especial de dilema: "É apropriado chamar uma mudança de perspectiva de radical ou de revolucionária apenas se a perspectiva posterior parece absurda a partir daquela anterior. Assim, por que não enxergamos aquelas mudanças como simplesmente irracionais?" (VAN FRAASSEN, 2002, p. 111). Com que fundamento tomamos a decisão de adotar (escolher, comprometer-nos com) uma visão de mundo que, de nosso ponto de vista atual, parece absurda?

Há aqui uma importante assimetria temporal. Podemos julgar razoáveis a perspectiva anterior e seu sucesso do ponto de vista da perspectiva sucessiva (pós-revolucionária), mas essa segunda é ininteligível, quando analisada a 
partir da visão de mundo originária. Assim, a pergunta, desconcertante, é como consegue uma comunidade racional (ou um indivíduo racional) passar de uma perspectiva a outra. Antigamente, ressalta van Fraassen, o empirismo tinha uma resposta simples e direta para tal questão. A experiência fornecia uma base sólida e independente de teorias que poderia servir para mostrar que a teoria anterior estava simplesmente errada. Tanto a teoria mais antiga quanto sua concorrente mais recente poderiam ser julgadas, tendo como referência o mesmo conjunto de evidências independentes de teorias. Desse modo, a visão posterior não resultava "ininteligível”, quando analisada a partir do ponto de vista da perspectiva anterior. Van Fraassen, porém, lembra que foi justamente sobre essa suposição de uma base granítica para o conhecimento que a versão anterior de empirismo naufragou.

A essa altura, a ideia de que a racionalidade seja simplesmente irracionalidade refreada volta a entrar em cena, ao fornecer um ponto de apoio para que possamos continuar a nos enxergar como seres racionais, durante todo o processo revolucionário de troca de teoria. "Mudanças de ponto de vista não são racionais porque são racionalmente forçosas; elas são racionais exatamente se são racionalmente permitidas, se não ultrapassam os limites da razão." (VAN FRAASSEN, 2002, p. 92). Note-se, todavia, que o voluntarismo epistêmico por si só não é suficiente para lidar com o problema da ininteligibilidade em perspectiva do novo. "Como é que podemos entender e considerar como um rival efetivo algo que sob a ótica atual nos parece absurdo?" (VAN FRAASSEN, 2002, p. 93).

A resposta de van Fraassen é que a revolucionária troca de teoria deve ser explicada, pelo menos em parte, por uma mudança de valores, que "[...] podemos entender somente sob o impulso da emoção, não como decisão factual ou teórica." (VAN FRAASSEN, 2002, p. 143). Ele se dirige à teoria das emoçôes de Sartre, para explicar de que modo uma rival que, sob a ótica presente, parece ininteligível pode se transformar em uma opção genuína. De acordo com Sartre, ele afirma, "[...] o fator central na emoção é representado por um certo tipo de mudança de ponto de vista que transforma nosso estado subjetivo. Isso fornece à emoção uma função cognitiva e volitiva bem definida." (VAN FRAASSEN, 2002, p. 104).

The Empirical Stance baseia-se, em grande medida, nas Terry Lectures de van Fraassen. Essa série de conferências trata com frequência da relação entre ciência e religiáo; vale notar que a última tem o título "O Que É A Ciência - e O Que Significa Ser Secular?” A conclusão dele é a de que a distinção 
entre o laico e o religioso reside na orientação e na atitude, "[...] em como encaramos o mundo e nos relacionamos com nossa própria experiência” (VAN FRAASSEN, 2002, p. 194), mais do que em teorias ou crenças acerca do mundo. Van Fraassen reafirma que vê as ciências empíricas como paradigma de racionalidade e enfatiza que modos de pesquisa que tendem à objetificação são essenciais para o sucesso da ciência moderna.

Mas, ao mesmo tempo, acredita que tais modos de pesquisa são inapropriados e inadequados, quando nos confrontamos com os outros, sejam eles humanos, sejam divinos. Adotar uma stance (objetificante) para nosso trabalho científico e uma stance diferente para nos confrontarmos com indivíduos não é inconsistente. Os metafísicos materialistas estão errados, afirma van Fraassen, em pensar que a relação entre ciência e secularismo seja de implicação lógica. Para poder defender que existe uma relação desse tipo, é necessário assumir que Deus e os outros indivíduos são mais bem estudados como "objetos científicos" - a própria suposição que se esforçam para rejeitar.

\section{O EMPIRISMo EsTrutural}

O empirismo estrutural é desenvolvido no livro que van Fraassen publicou em 2008, Scientific Representation: Paradoxes of Perspective. É oportuno que o leitor atente para o fato de que, embora o empirismo estrutural combine muito bem com o empirismo construtivo, ele não depende desse último; $\mathrm{e}$ van Fraassen espera que os empiristas de espécies variadas achem o empirismo estrutural atrativo. Representa sua resposta antirrealista ao realismo estrutural.

Os realistas estruturais admitem que o realismo tradicional acerca das entidades teóricas não é defensável; termos teóricos que, sob a ótica presente, parecem ter um referente real (ainda que inobservável) poderiam ficar desprovidos de referente, depois da próxima revolução científica. Eles defendem, em alternativa, que o constante sucesso da ciência se explica pelo fato de teorias sucessivas preservarem boa parte da estrutura das teorias anteriores. Isso está refletido na relação que podemos retrospectivamente identificar entre as fórmulas matemáticas de teorias antecessoras e sucessoras. As estruturas matemáticas que são preservadas através de sucessivas revoluçóes científicas são aquelas que espelham a estrutura da realidade.

Essa, evidentemente, não é uma posição que van Fraassen pode aceitar. Ele frisa que a alternativa que propóe, o empirismo estrutural, não é uma 
visão acerca da natureza, mas uma visão acerca da ciência. O "estrutural" de "empirismo estrutural" não faz referência à estrutura do mundo subjacente, mas apenas, sublinha van Fraassen, ao fato de toda representação científica ser, em seu íntimo, matemática (VAN FRAASSEN, 2008, p. 238-239). E o lema "tudo que conhecemos é estrutura" significa apenas isso: a ciência representa os fenômenos empíricos como encaixáveis em certas estruturas abstratas (a saber, modelos teóricos), e tais estruturas podem ser descritas somente até o ponto de um isomorfismo estrutural.

Essa posição é extremamente austera e poderia não estar claro de que maneira essas estruturas matemáticas conseguem conectar-se, de modo adequado, aos fenômenos que deveriam representar. O que converte um objeto puramente matemático em uma representação de relaçóes específicas entre fenômenos? O "estruturalismo extremo" de Bertrand Russell sofreu um ataque devastador, em 1928, por obra de M. H. A. Newman, o qual mostrou que, se dois conjuntos apresentam igual cardinalidade, então, a correspondência um a um entre eles pode ser utilizada para selecionar, em um conjunto, uma cópia de qualquer estrutura relacional no outro. Weyl tinha escrito, em 1934, que a ideia de isomorfismo "[...] indica a consciência da barreira intransponível" do conhecimento científico (VAN FRAASSEN, 2008, p. 19). E, obviamente, o programa das definiçóes coordenativas de Reichenbach, como um instrumento que permitiria conectar o mundo às suas representaçôes teóricas, tinha fracassado. Essa "perda de realidade" é um espectro que assombra boa parte do livro. Como podemos então estabelecer uma conexão entre os fenômenos (ou seja, a realidade) e as estruturas matemáticas que utilizamos como modelos teóricos?

Van Fraassen introduz duas distinções que são importantes para entender tanto essa questão quanto a resposta. A primeira é uma distinção entre os "fenômenos" e as "aparências". Anteriormente, os dois termos tinham sido usados de forma quase intercambiável. Agora, entretanto, definiçóes estipulativas são introduzidas para realizar uma importante diferenciação entre os dois. Fenômenos são entidades observáveis: objetos, eventos e processos. Aparências são os conteúdos da observação ou resultados de medições. Assim, os fenômenos apresentam algum tipo de realidade, enquanto as aparências são representaçóes desses fenômenos.

Isso nos leva à segunda distinçáo crucial. As aparências são representaçóes perspécticas (ou seja, retratos) de fenômenos. Elas não nos dizem como os fenômenos são, mas apenas como aparecem em uma dada 
medição ou mecanismo de observação. Esse, evidentemente, é um ponto particularmente pertinente, no caso de mediçóes quânticas, o que influencia grande parte do argumento, aqui como alhures, mas é generalizado para cobrir todas as aparências. Com efeito, questôes de perspectiva permeiam Scientific Representation. Todas as imagens são perspécticas, de acordo com van Fraassen, mas nem todas as representaçóes são imagens. Esse é um ponto de importância crucial, pois nele se apoia a sua distinção entre a visão da ciência "de dentro" e a visão "de cima". Nós adotamos perspectivas, quando desenvolvemos e utilizamos teorias no interior de um determinado contexto histórico, mas a "versão oficial" das teorias científicas em geral, ou seja, a visão "de cima", é desprovida de perspectiva.

Para van Fraassen, questóes de perspectiva têm mais a ver com consideraçóes de tipo pragmático do que representar uma característica própria da ciência. Aqui, como em outras partes, parece-nos possível enxergar traços de sua descendência do empirismo lógico. Assim como se considerou que o "contexto da descoberta" e os fatores que o influenciavam não faziam propriamente parte da ciência, do mesmo modo, os elementos históricos e pragmáticos desaparecem da "versão oficial" da ciência de van Fraassen. Ele sugere, todavia, que a visão "de dentro" e a visão "de cima” sejam reunidas em uma única visão sinóptica, ao mesmo tempo que é negado que tanto a visão de cima quanto aquela sinóptica pressuponham uma "visão com os olhos de Deus".

Munidos dessas duas distinçóes, fenômenos/aparências e representações perspécticas/ representaçóes desprovidas de perspectiva, podemos voltar à questão de como fazer para estabelecer uma ligação entre os fenômenos (a saber, entidades observáveis, processos e eventos) e as estruturas matemáticas que utilizamos como seus modelos teóricos.

As aparências dos fenômenos (isto é, os resultados de mediçôes) são conjuntos de dados matemáticos refinados em modelos de dados, os quais são em seguida idealizados, até se tornarem modelos de superfície. O objetivo é encaixar tais modelos de superfície em modelos da teoria de interesse. Os fenômenos em si não podem ser incluídos em modelos teóricos, pois eles, afinal, não são objetos matemáticos. Apenas as representaçôes perspécticas dos fenômenos, as quais resultam de tipos específicos de mediçóes que escolhemos levar a cabo, são candidatas à incorporação. A relação entre as aparências e os modelos teóricos nos quais elas são incluídas parece explícita; trata-se de uma relação matemática. Mas qual é a relação entre os fenômenos e essas 
representaçôes matemáticas? Esse é um assunto de grande importância, pois van Fraassen continua definindo a adequação empírica em termos de "salvar os fenômenos" - e não salvar as aparências. Como podemos estabelecer a conexão apropriada entre o mundo físico e nossos modelos teóricos?

A resposta curta é que "[...] a construção de um modelo de dados constitui precisamente a descrição seletiva e pertinente dos fenômenos, pelo usuário da teoria, necessária para poder representar os fenômenos." (VAN FRAASSEN, 2008, p. 253). A resposta mais completa depende do estabelecimento de uma tautologia pragmática, nos moldes do Paradoxo de Moore: uma afirmação que seja logicamente contingente, mas inegável. Moore, como bem se sabe, defendeu que um indivíduo não pode afirmar, de modo consistente, " $p$, porém eu não acredito que $p$ ". A suposta contradição é descrita como sendo pragmática, em vez de lógica, pois é dita depender do ato de afirmação em primeira pessoa.

Van Fraassen constrói sua própria tautologia pragmática, para fins de neutralizar a objeção segundo a qual, de acordo com seu novo relato, a adequação empírica não seria mais adequação aos fenômenos, mas apenas adequação às aparências (ou seja, adequação aos fenômenos assim como eles são representados em nossos modelos matemáticos). Se a adequação empírica é assim definida como uma mera relação entre dois modelos matemáticos, então, parece mesmo que perdemos o contato com a realidade. Van Fraassen tenta reestabelecer a conexão, recorrendo a um tipo de indexicalidade.

$\mathrm{O}$ argumento seria:

Para nós as afirmações

(A) que a teoria é adequada aos fenômenos e a afirmação

(B) que é adequada aos fenômenos tal como representados, ou seja, como representados por nós, são de fato a mesma coisa.

Que (A) e (B) sejam a mesma coisa é para nós uma tautologia pragmática. (VAN FRAASSEN, 2008, p. 259).

De acordo com van Fraassen, afirmar “(B), mas não (A)", nesse contexto (isto é, afirmar que a teoria é adequada às aparências, mas não aos fenômenos), seria o mesmo que dizer " $p$, porém eu não acredito que $p$ ”. A analogia com o Paradoxo de Moore deve ser levada a sério, e a dependência do ato de afirmação em primeira pessoa é crucial. Ela representa um tipo de indexicalidade, a 
qual aqui é caracterizada como uma consideração de cunho pragmático. Van Fraassen associa isso à metáfora do mapa, que tem utilizado nas últimas duas décadas: "Afirmar que um certo diagrama representa os fenômenos que estou observando e medindo equivale a afirmar que um determinado ponto em um mapa corresponde ao local onde me encontro." (VAN FRAASSEN, 2008, p. 257). Muito está em jogo aqui. Se as afirmaçôes de indexicalidade não funcionassem (e não está totalmente claro que funcionem), o estruturalismo empirista perderia efetivamente seu gancho com a realidade.

Foi sugerido anteriormente que a austeridade da filosofia da ciência antirrealista de van Fraassen e a sua minimização do risco epistêmico podem ser vistas como aliadas de seu voluntarismo epistêmico, no sentido de que uma deixa ampla liberdade de açáo para ao outro. Embora o voluntarismo epistêmico não desempenhe um papel especialmente relevante, em Scientific Representation, um esforço significativo é dedicado à defesa da austeridade, particularmente na última parte do livro, intitulada "Aparência e Realidade" ("Apearance and Reality"). Há nela um ataque a vários critérios de completude que têm sido influentes, durante diferentes períodos da história da ciência critérios que vão além da adequação empírica, para satisfazer nosso desejo de explicação, inteligibilidade e unidade.

De acordo com van Fraassen, o progresso da ciência levou a revisóes sucessivas de tais critérios. O requisito aristotélico de explicaçóes necessárias deu lugar, no século XVII, a um pedido de explicações determinísticas. Por sua vez, tal critério teve problemas com a mecânica quântica e, para acomodar o indeterminismo ao mesmo tempo que tentava manter alguma regra, Reichenbach introduziu o Princípio de Causa Comum. O critério de completude presente, que van Fraassen chama de Critério da Aparência da Realidade (Apearance from Reality Criterion), constitui uma resposta ao reconhecimento de que a mecânica quântica viola as desigualdades de Bell, forçando-nos assim a desistir de qualquer tipo de princípio de causa comum. O novo critério exige da ciência que ela demonstre "[...] que, e de que modo, essas aparências são produzidas como sendo uma parte legítima da realidade representada." (VAN FRAASSEN, 2008, p. 281). Entretanto, acrescenta van Fraassen, o desenvolvimento de Copenhague da mecânica quântica constitui uma clara rejeição dessa demanda; e assim, mais uma vez, o progresso da ciência exige que desistamos até mesmo de um critério de completude enfraquecido.

É oportuno salientar, mais uma vez, que o empirismo construtivo e o estruturalismo empirista são posiçóes distintas. $\mathrm{O}$ ponto aqui é apenas que a 
recusa de van Fraassen de qualquer pedido de explicação que faça referência a uma realidade subjacente está no cerne das duas. Em nenhum dos dois casos se segue automaticamente que nós somos irracionais, se optarmos por adotar crenças que vão além daquelas que a ciência exige. Se tais crenças não são proibidas (por consideraçôes de consistência lógica ou de adequação empírica, por exemplo), então são permitidas. Van Fraassen se mantém claramente "inglês" aqui, em nítido contraste com o aspecto muito "prussiano" do caráter de sua definição do objetivo da ciência, em termos de adequaçáo empírica apenas, que limita o comprometimento ao essencial.

\section{CONSIDERAÇÓEs FinaIS}

Se William James aparece como um dos heróis de van Fraassen, em discussóes a respeito do voluntarismo epistêmico, William Kingdon Clifford interpreta o papel de viláo e de contraponto. Em seu artigo de 1877, "The Ethics of Belief", Clifford notoriamente afirmou que [...] "está errado sempre, em qualquer lugar e para qualquer um, acreditar em algo com base em evidência insuficiente." (CLIFFORD, 1877, p. 77). É esse o artigo que foi alvo de ataque por William James, em "The Will to Believe". No presente contexto, vale provavelmente a pena notar que, se a epistemologia voluntarista de van Fraassen é, sob muitos aspectos, existencialista jamesiana, sua filosofia da ciência lembra mais Clifford. Sua definição do objetivo da ciência como sendo (apenas) a adequação empírica implica que, na ciência, não pode haver justificação suficiente -nunca, em nenhum lugar, para ninguém - que permita acreditar que nossas teorias sáo verdadeiras.

A permissividadede jamesiana da epistemologia de van Fraassen e a austeridade à la Clifford de sua filosofia da ciência caminham de máos dadas. James afirmou que, quando os dois propósitos, acreditar na verdade e evitar o erro, nos puxam para direções distintas, a escolha de evitar o erro é tanto uma questão de decisão passional quanto a escolha de buscar a verdade para além da evidência. Embora van Fraassen forneça muitos argumentos extremamente inteligentes em favor de sua filosofia da ciência, a escolha de definir o objetivo da ciência como sendo (apenas) a adequação empírica poderia também ser vista como uma escolha passional, a qual deixa ampla margem para a ação da vontade em outras atividades racionais. 


\section{Leituras AdicionaIs}

A literatura que inclui análises dos argumentos de van Fraassen e respostas aos mesmos é vasta. Algumas amostras de recursos úteis poderiam ser as seguintes:

- O artigo "Constructive Empiricism", da Stanford Encyclpedia of Philosophy, escrito por Bradley Monton e Chad Mohler. Esse é um excelente texto com o qual começar, para argumentos e objeçóes standard.

- Images of Science, editado por Paul Churchland e Clifford Hooker. O subtítulo desse volume é "Essays on Realism and Empiricism, with a Reply from Bas C. van Fraassen”. Os dez ensaios são de autores de destaque, na filosofia da ciência, e oferecem um bom panorama das primeiras respostas a The Scientific Image.

- Images of Empiricism, editado por Bradley Monton. O subtítulo é "Essays on Science and Stances, with a Reply from Bas C. van Fraassen”. Aqui, também, os ensaios são de autores de destaque na área. A gama de assuntos é ampla e a discussão não está limitada a The Empirical Stance.

\section{Breve Biografia}

Kathleen Okruhlik trabalhou como filósofa da ciência em The University of Western Ontario, por mais de 30 anos. Graduou-se em Filosofia na Marquette University. Mestrado e Doutorado em História e Filosofia da Ciência foram obtidos na University of Pittsburgh. Seus interesses residem na filosofia da ciência feminista e em abordagens mais "tradicionais". O primeiro livro de filosofia da ciência que leu, quando era graduanda, foi a obra de van Fraassen de 1970, An Introduction to the Philosophy of Time and Space, e o primeiro artigo que publicou, depois de um longo período na administração universitária, foi uma nota crítica ao livro de 2008 do mesmo autor, Scientific Representation, publicada no Canadian Journal of Philosophy (v. 39, p. 671694). Sua palestra inaugural do HOPOS 2012 também forneceu uma base útil para o presente ensaio. O título da palestra foi: "Irracionalidade Controlada: Antecessores Históricos do Voluntarismo Epistêmico de Bas van Fraassen" ("Historical Antecedents of Bas van Fraassen's Epistemic Voluntarism"). Recentemente, publicou um artigo intitulado "Science, Sex and Pictures", o 
qual critica alguns aspectos do empirismo de van Fraassen, a partir do ponto de vista da análise feminista da ciência.

\author{
Nota \\ * Correspondência: Philosophy, The University of Western Ontario, London, \\ ON, Canada. Email: okruhlik@uwo.ca
}

GAVA, A. Bas van Fraassen's Philosophy of Science and His Epistemic Voluntarism. Trans/ form/ação, Marília, v. 44, n. 4, p. 375-398, Out./Dez., 2021.

\begin{abstract}
Bas van Fraassen's anti-realist account of science has played a major role in shaping recent philosophy of science. His constructive empiricism, in particular, has been widely discussed and criticized in the journal literature and is a standard topic in philosophy of science course curricula. Other aspects of his empiricism are less well known, including his empiricist account of scientific laws, his relatively recent re-evaluation of what it is to be an empiricist, and his empiricist structuralism. This essay attempts to provide an overview of these diverse aspects of van Fraassen's empiricism and to show how they relate to one another. It also focuses on the nature of van Fraassens's epistemic voluntarism and its relationship to his empiricist philosophy of science.
\end{abstract}

Keywords: Anti-realism. Constructive empiricism. Empiricist structuralism. Epistemic voluntarism. van Fraassen.

\title{
Trabalhos Citados
}

CHURCHLAND, P. M.; HOOKER, C. A. (ed.). Images of Science. Chicago: University of Chicago Press, 1985.

CLIFFORD, W. K. The ethics of belief. In: MADIGAN, T. (ed.). The ethics of belief and other essays. Amherst, MA: Prometheus, 1877 [1999]. p. 70-96.

MONTON, B. (ed.). Images of Empiricism. Oxford: Oxford University Press, 2007.

MONTON, B.; MOHLER, C. Constructive Empiricism. The Stanford Encyclopedia of Philosophy. Winter 2012 ed. Ed. Edward. N. Zalta. Stanford, CA: The Metaphysics Research Lab Center for the Study of Language and Information, Stanford University, 2012. Disponível em: http://plato.stanford.edu/archives/win2012/entries/constructiveempiricism. Acesso em: 10 jan. 2020. 
OKRUHLIK, K. Critical Notice: Bas van Fraassen, Scientific Representation: Paradoxes of Perspective. Canadian Journal of Philosophy, v. 39, n. 4, p. 671-694, 2009.

OKRUHLIK, K. Science, Sex, and Pictures: Reflections on van Fraassen's Use of Perspectival Representations. In: GAO, G.; LIU, C. (ed.). Scientific Explanation and Methodology of Science. Singapore: World Scientific, 2014. p. 156-169.

VAN FRAASSEN, B. C. An Introduction to the Philosophy of Time and Space. New York: Random House, 1970.

VAN FRAASSEN, B. C. The Scientific Image. Oxford: Oxford University Press, 1980.

VAN FRAASSEN, B. C. Belief and the Will. The Journal of Philosophy, v. 81, n. 5, p. 235-256, 1984.

VAN FRAASSEN, B. C. Laws and Symmetry. Oxford: Oxford University Press, 1989.

VAN FRAASSEN, B. C. Quantum Mechanics: An Empiricist View. Oxford: Oxford University Press, 1991.

VAN FRAASSEN, B. C. The Empirical Stance. New Haven: Yale University Press, 2002.

VAN FRAASSEN, B. C. Scientific Representation: Paradoxes of Perspective. Oxford: Oxford University Press, 2008.

Recebido: $14 / 5 / 2020$

Aceito: 03/8/2020 
GAVA, A. 